\title{
Pengenalan Profile Sekolah Pada SMA Islam Terpadu Asy-Syukriyyah Tangerang Berbasis Web
}

\author{
Yuni Roza ${ }^{1}$ \\ Arif Novrizal $^{2}$ \\ Jihan Tiffaanillah Emha ${ }^{3}$ \\ 1,2 Program Studi Manajemen Informatika Fakultas Sains Dan Teknologi, Universitas Raharja \\ ${ }^{3}$ Program Studi Sistem Informasi Fakultas Sains Dan Teknologi, Universitas Raharja \\ Email : ${ }^{1}$ yuni.roza@ raharja.info,${ }^{2}$ arif.novrizal@ raharja.info,${ }^{3}$ jihan.tiffaanillah@ raharja.info
}

\begin{abstract}
Abstrak
SMA Islam Terpadu Asy-Syukriyyah adalah sekolah yang telah menjalankan sebuah sitem informasi dan sistem informasi yang berjalan saat ini pun masih dapat dikatakan semi terkomputerisasi seperti pengumuman sebuah informasi promosi sekolah yang masih menggunakan media majalah dinding, brosur dan banner yang dalam prosesnya memakan waktu dan biaya yang mahal sehingga tidak ekonomis dan kurang efektif. Untuk metode analisa terhadap sistem yang berjalan dengan tujuan untuk merancang sistem yang baru maka menggunakan metode analisa PIECES (Performance, Information, Economy, Control, Eficiency, and Service). Dan metode perancangan yang menggunakan UML (Unified Modelling Language). Dengan adanya sebuah rancangan sistem informasi yang menggunakan website, hal ini diharapkan dapat menghemat biaya produksi penyebaran informasi yang masih menggunakan banner maupun brosur sebagai media informasi pengenalan sekolah kepada calon siswa/i, serta semakin memperluas jangkauan informasi sekolah melalui media website yang dirancang agar bisa diakses oleh banyak calon siswa/i atau pengunjung yang mencari informasi seputar SMA Islam Terpadu Asy-Syukriyyah baik dari Tangerang maupun diluar Tangerang.
\end{abstract}

Kata Kunci : Informasi,Website, PIECES, Banner.

\section{Abstract}

SMA Islam Terpadu Asy-Syukriyyah is a school that has run an information system and an information system that is running today can still be said to be semi-computerized, such as the announcement of a school promotion information that still uses wall magazines, brochures and banners, which in the process takes time and costs. expensive so it is not economical and less effective. For the analysis method of a running system with the aim of designing a new system, the PIECES (Performance, Information, Economy, Control, Efficiency, and Service) analysis method is used. And the design method using UML (Unified Modeling Language). With the existence of an information system design that uses a website, it is hoped that it can save the production costs of disseminating information that still uses banners and brochures as an information medium for introducing schools to prospective students, and further expanding the reach of school information through website media designed to be accessible by many prospective students or visitors who are looking for information about the Asy-Syukriyyah Integrated Islamic High School both from Tangerang and outside Tangerang.

Keywords:Information, Website, PIECES, Banner. 


\section{PENDAHULUAN}

Perkembangan teknologi dan informasi telah menjadi suatu hal yang selalu berkembang saat ini.Salah satu bentuk teknologi yang berpengaruh adalah teknologi untuk memberikan informasi dan pelayanan yang cepat.Website adalah bentuk nyata dalam pegoperasian suatu jaringan global.Setiap instansi atau organisasi telah menggunakan teknologi website untuk berbagai keperluan, sebagai media promosi, pemberitaan dan lain sebagainya.Tidak hanya satu bidang saja, mulai dari bidang kesehatan, pertanian, dan pendidikan telah menggunakan website untuk meningkatan pelayanan dibidangnya.Sebuah instansi pendidikan saat ini selalu mengupayakan peningkatan sebuah sistem manajemen informasi dengan tujuan untuk menjadi lebih baik dalam hal pelayanan informasi sebagai media promosi agar efektif dan efisien. SMA Islam Terpadu Asy-Syukriyyah adalah sekolah yang telah menjalankan sebuah sitem informasi dan sistem informasi yang berjalan saat ini pun masih dapat dikatakan semi terkomputerisasi seperti pengumuman sebuah informasi promosi sekolah yang masih menggunakan majalah mading, brosurdan banner yang memakan waktu sehingga tidak ekonomis dan kurang efektif. Dengan berbagai masalah tersebut mendorong penulis untuk membuat sebuah Website pengenalan profile sekolah dengan tujuan untuk memberikan solusi pengenalan profile sekolah kepada calon siswa/i yang ingin mencari informasi seputar sekolah.

\section{TINJAUAN PUSTAKA}

\section{Sistem Informasi}

Sistem informasi adalah suatu sistem yang berhubungan dengan pengumpulan, penyimpanan dan pemrosesan data, baik yang dilakukan secara manual, maupun bantuan komputer, untuk menghasilkan informasi yang sangat berguna bagi proses pengambilan keputusan.[1]

\section{Informasi}

Informasi adalah data yang diolah menjadi bentuk yang lebih berguna dan lebih berarti bagi penerimanya.[2]

\section{Perancangan}

Perancangan pennggambaran, perencanaan dan pembuatan sketsa atau pengaturan dari beberapa elemen yang terpisah ke dalam satu kesatuan yang utuh dan berfungsi.[3]

\section{Website}

Website atau web adalah jaringan komputer yang terdiri dari kumpulan situs internet yang menawarkan teks dan grafik dan suara dan sumber daya animasi melalui hypertext transfer protocol. $[4]$

\section{METODE PENELITIAN}

Metode yang peneliti gunakan pada penelitian ini adalah :

1. Metode Pengumpulan Data

Dalam memperoleh data yang di inginkan, maka harus menggunakan beberapa metodemetode. Adapun metode-metode yang akan digunakan sebagai berikut :

a. Observasi

Peneliti melakukan pengamatan langsung pada SMA Islam Terpadu Asy-syukriyyah agar mendapat data-data yang dibutuhkan dalam penulisan dan membantu dalam menganalisa untuk membangun rangka sistem tersebut.

b. Wawancara

Peneliti melakukan tanya jawab dengan Bapak Harun Zein selaku WAKABID Kepegawaian SARPRAS SMA Islam Terpadu Asy-Syukriyyah Tangerang. Metode ini 
dilakukan untuk mengetahui informasi secara spesifik agar mudah dan terarah dalam mengambil suatu tindakan yang akan dilakukan.

c.

Studi Pustaka

Metode untuk mendapatkan informasi dan data dari beberapa sumber atau dengan membaca dan mempelajari buku-buku yang relevan dengan judul penulis.Data-data tersebut digunakan untuk membantu penganalisaan dan perancangan laporan yang terkait.

2. Metode Analisa

Tahap Analisa merupakan tahap penelitian terhadap sistem yang berjalan dengan tujuan untuk merancang sistem yang baru.Analisa sistem ini dilakukan dengan metode Analisa PIECES (Performance, Information, Economy, Control, Eficiency, and Service). Analisa PIECES ini sangat penting dilakukan sebelum mengembangkan sebuah system informasi, karena dalam analisis ini biasanya akan ditemukan beberapa masalah utama maupun masalah yang bersifat gejala dari masalah utama. Alat bantu yang digunakan dalam metode ini adalah Unified Modelling Language (UML), yang dibuat menggunakan software visual paradigm.

\section{LITERATUR RIVIEW}

1. Abdul Mubarak, dalam JIKO (Jurnal Informatika dan Komputer) Ternate Vol. 02 No. 1, April 2019 yang berjudul "Rancang Bangun Aplikasi Web Sekolah Menggunakan UML (Unified Modeling Language) dan Bahasa Pemrograman PHP (PHP Hypertext Preprocessor) Berorientasi Objek". Tujuan dari penelitian ini adalah untuk rancang bangun aplikasi web sekolah menggunakan alat perancangan UML (Unified Modeling Language) dan bahasa pemrograman PHP (PHP Hypertext Preprocessor) di SMK IndTim Makassar. Hasil dari penelitian ini adalah aplikasi web sekolah yang dapat digunakan oleh sekolah untuk menyebarluaskan informasi sekolah.[5]

2. Enang Rusnandi, dalam INFOTECH Journal Vol. 3 No. 22017 yang berjudul "Perancangan Web Sekolah dan PPDB Online MTs Negeri Karangsambung". Tujuan dari penelitian ini adalah untuk sistem informasi pendaftaran penerimaan peserta didik baru secara online diharapkan mempunyai keunggulan dari pada pendaftaran manual. Keunggulan yang diharapkan disini seperti mementingkan kenyamanan pendaftar yang nantinya bertujuan untuk mencapai keefektifan waktu, dimana dengan sistem ini, para pendaftar yang berada diluar kota Surakarta dapat dengan mudah mendaftar tanpa harus datang ke sekolah. perancangan web sekolah dan PPDB online pada MTs Negeri Karangsambung.[6]

3. Tinjauan studi pustaka dari penelitian Miranda Ayu Damayanti, Sudaryanto dalam Journal of Information System Vol. 5, No. 2, Nopember 2020 yang berjudul "Sistem Informasi Akademik Berbasis Web Pada SMA Negeri 13 Semarang". Tujuan dari penulisan jurnal ini adalah untuk memaksimalkan pemanfaatan dan penerapan teknologi informasi, kumpulan data yang saling berhubungan satu sama lain dapat diorganisasikan menjadi sebuah file basis data, dimana data diorganisasikan kemudian disimpan kedalam basis data untuk memudahkan pemakai dalam mengakses data. Metode yang digunakan dalam perancangan sistem ini adalah Rapid Application Development $(R A D)$ dan perancangan sistem alat yang dipakai adalah Unified Modeling Language (UML) yang terdiri dari usecase diagram, sequence diagram, class diagram, dan activity diagram. Teknik pengumpulan data dilakukan secara observasi dan wawancara. Hasil dari penelitian ini adalah suatu aplikasi sistem akademik sekolah berbasis webite, sebuah web yang dibuat untuk mempermudah aktifitas akademik di SMA Negeri 13 Semarang.[7]

4. Tinjauan studi pustaka dari penelitian Sumartono dkk dalam JPP IPTEK (Jurnal Pengabdian dan Penerapan IPTEK) Vol. 4 No. 1, Mei 2020 yang berjudul "PPM Pelatihan Pembuatan dan Pengelolaan Web SMA Dharma Wanita 4 Taman, Sidoarjo". Tujuannya adalah untuk membangun WEB sekolah dan memberikan pelatihan kepada guru bagaimana untuk 
mengelola WEB sekolah. Karena Web resmi untuk suatu institusi pendidikan adalah kebutuhan yang tidak dapat dihindari. Oleh sebab itu pihak sekolah SMA Dharma Wanita 4 Sidoarjo membutuhkan pelatihan untuk guru-guru dan atau karyawan untuk dapat mengelola web institusi tersebut.[8]

5. Tinjauan studi pustaka dari penelitian Eko Yulianto dkk dalam Jurnal TECHNO Nusa Mandiri Vol. 15, No.1 Maret (2108) yang berjudul "Sistem Informasi Akademik Penilaian Berbasis Web Pada SMA Mandiri Balaraja - Kab. Tangerang". Tujuan penelitian ini adalah karena SMA Mandiri Balaraja - Kab. Tangerang ingin terus berupaya agar mampu mengimbangi perkembangan dunia pendidikan untuk bersaing dan dapat diandalkan. Sistem penilaian yang masih manual dan belum terkomputerisasi. Hal ini menyebabkan kesulitan dalam melakukan proses penilaian, karena banyak memerlukan berkasberkas yang harus dicatat. Sistem informasi akademik pengolahan nilai berbasis web menjawab permasalahan tersebut, karena dapat di akses online dimana saja dan kapan saja dengan jaringan internet.[9]

6. Tinjauan studi pustaka dari penelitian Benny Suhendar dkk dalam Jurnal Sistem Informasi dan Informatika (SIMKA) Vol. 1 No. 1 (2018) yang berjudul "Analisa Dan Perancangan Sistem Informasi Sekolah Berbasis Web di SMA 2 Kota Serang”. Tujuan dari penulisan ini adalah untuk membantu orang tua siswa dalam menentukan sekolah mana yang sesuai dengan putra-putrinya. Dari hasil Analisa dan Perancangan ini dikembangkan kebentuk suatu sistem yang dapat menyampaikan informasi sekolah di Kabupaten atau Kota untuk membantu orang tua siswa dalam menentukan sekolah yang sesuai dengan putra-putri mereka.[10]

7. Limin Gu dari United University di Swedia dalam Nordic Journal Of Studies In Educational Policy Vol. 3 No. 2, tahun 2017 yang berjudul "Using School Websites for Home-School Communication and Parental Involvement?" menjelaskan tujuan dari dibuatnya penelitian adalah untuk menjelajahi, mendeskripsikan, dan membandingkan apa dan bagaimana relevansi mengenai informasi yang disampaikan langsung dari sekolah dan yang tertera di website sekolah sebagaimana peran website sekolah yang mewakili persepsi sekolah itu sendiri. Selain itu dijabarkan mengenai peran website sekolah sebagai salah satu strategi dalam berkomunikasi dengan keluarga \& orangtua murid, serta website dapat menjadi media marketing yang baik guna memberi informasi mengenai suatu sekolah.[11]

\section{HASIL DAN PEMBAHASAN}

Dari penelitian yang dilakukan, sistem pengenalan profile sekolah kepada calon siswa/i sudah berjalan dengan baik dengan menggunakan media cetak seperti banner dan brosur.Namun hal ini dirasa kurang efektif jika menerapkan sistem yang seperti itu karena untuk pemasangan banner pasti memerlukan tempat yang strategis dan memerlukan biaya yang relatif mahal.Juga tidak menjamin banyak calon siswa/i yang melihat baner tersebut, karena hanya bisa dilihat dilokasi dipasangnya baner.Dari permasalahan tersebut maka dibuatkanlah analisa PIECES (Performance, Information, Economy, Control, Eficiency, and Service).Dan analisa sistem yang disajikan dalam gambar Unified Modeling Language (UML) yang terdiri dari Use Case Diagram, Activity Diagram, dan Sequence Diagram.Seperti gambar dibawah ini :

\section{Analisa PIECES}

Tabel 1. Analisa PIECES

\begin{tabular}{|l|c|l|l|l|}
\hline NO & Jenis Annaisis & \multicolumn{2}{|c|}{ Sistem Yang Berjalan } & Sistem Yang Diusulkan \\
\hline 1. & Performance & Penggunaan banner kurang & Bisa dilihat oleh siapa saja dan \\
& (Kinerja) & efektif karena pemasanganya & kapan saja secara online. \\
& & yang monoton dan tidak & \\
& & semua & orang & bisa
\end{tabular}




\begin{tabular}{|c|c|c|c|}
\hline & & melihatnya. & \\
\hline 2. & $\begin{array}{c}\text { Information } \\
\text { (Informasi) }\end{array}$ & 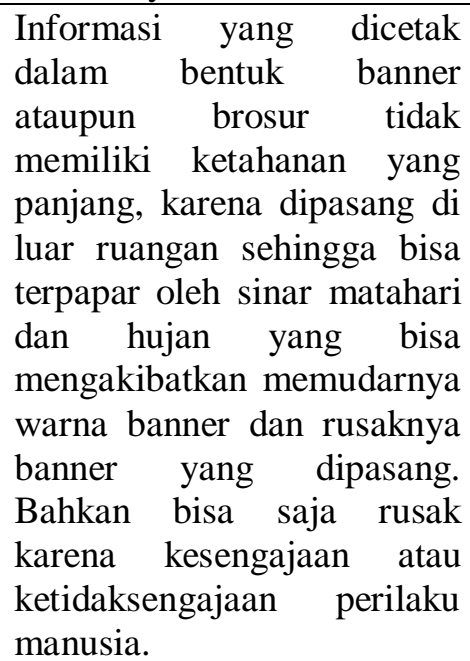 & $\begin{array}{l}\text { Pemasangan informasi di } \\
\text { banner dan brosur di } \\
\text { aplikasikan pada website agar } \\
\text { jangkauan akses informasi } \\
\text { lebih luas serta kemudahan } \\
\text { mendapatkan informasi yang } \\
\text { bisa diakses melalui perangkat } \\
\text { elektornik. Namun tetap tidak } \\
\text { menghilangkan penggunaan } \\
\text { keduanya sebagai bentuk } \\
\text { penyebaran informasi sekolah. }\end{array}$ \\
\hline 3. & $\begin{array}{l}\text { Economic } \\
\text { (Ekonomi) }\end{array}$ & $\begin{array}{l}\text { Menggunakan media cetak } \\
\text { seperti banner dan brosur } \\
\text { sebagai } \\
\text { informasinya penyebaran } \\
\text { memerlukan biaya lebih. }\end{array}$ & $\begin{array}{l}\text { Tidak menggunakan media } \\
\text { cetak karena bentuk brosur } \\
\text { maupun banner bisa dijadikan } \\
\text { format PDF didalam website. } \\
\text { Dan penjabaran informasi bisa } \\
\text { lebih detail karena bisa disertai } \\
\text { video dan foto yang terbaru. }\end{array}$ \\
\hline 4. & $\begin{array}{c}\text { Control } \\
\text { (Pengendalian) }\end{array}$ & $\begin{array}{l}\text { Pemasangan } \\
\text { informasi sekolah yanner } \\
\text { jarang terkontrol oleh pihak } \\
\text { sekolah sehingga berbagai } \\
\text { bentuk kerusakan yang } \\
\text { sengaja ataupun tidak } \\
\text { disengaja mengakibatkan } \\
\text { tidak bisa segera dilakukan } \\
\text { tindakan perbaikan atau } \\
\text { penggantian pada banner } \\
\text { informasi tersebut. }\end{array}$ & $\begin{array}{l}\text { Admin website lebih mudah } \\
\text { melakukan control informasi } \\
\text { sekolah dan mudah untuk } \\
\text { melakukan update sebuah } \\
\text { informasi dan melakukan } \\
\text { maintenance pada website. }\end{array}$ \\
\hline 5. & $\begin{array}{l}\text { Eficiency } \\
\text { (Efisiensi) }\end{array}$ & $\begin{array}{l}\text { Penggunaan banner dan } \\
\text { brosur untuk informasi } \\
\text { sekolah harus dipasang } \\
\text { ditempat yang strategis agar } \\
\text { mudah dilihat oleh orang- } \\
\text { orang atau calon siswa/i } \\
\text { namun tidak semua tempat } \\
\text { akan dilalui oleh calon } \\
\text { siswa/i. }\end{array}$ & $\begin{array}{l}\text { Penyajian informasi dalam } \\
\text { website lebih mudah diakses } \\
\text { dan jangkauannya luas serta } \\
\text { data pegumuman atau } \\
\text { informasi sekolah telah } \\
\text { tersimpan dalam database } \\
\text { sehingga mudah untuk mencari } \\
\text { informasi sekolah. }\end{array}$ \\
\hline 6. & $\begin{array}{c}\text { Service } \\
\text { (Pelayanan) }\end{array}$ & $\begin{array}{l}\text { Tidak semua sisi banner } \\
\text { dapat terlihat dengan jelas } \\
\text { karena yang melihat pasti } \\
\text { dari berbagai sudut pandang } \\
\text { yang berbeda sehingga } \\
\text { terjadilah multi tafsir dalam } \\
\text { memahami informasi } \\
\text { sekolah. }\end{array}$ & $\begin{array}{l}\text { Banyak informasi yang } \\
\text { disediakan mulai dari kegiatan } \\
\text { sekolah, prestasi siswa/i, } \\
\text { pengumuman } \\
\text { informasi pendaftaran, artikel } \\
\text { sekolah. Semua itu dapat } \\
\text { diakses dengan mudah dengan } \\
\text { perangkat elektronik secara }\end{array}$ \\
\hline
\end{tabular}


ISSN: 2461-1409

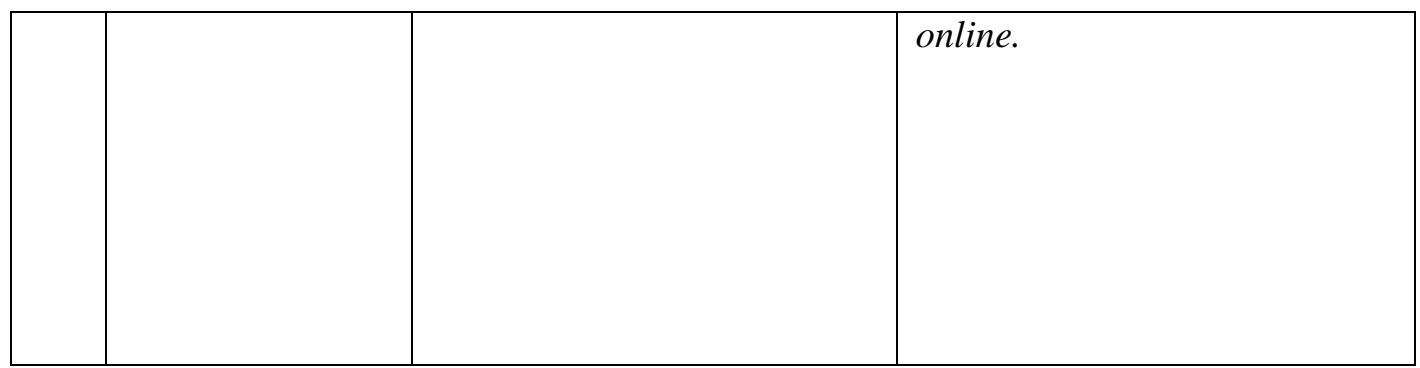

2. Analisa Sistem Dengan UML Diagram 2.1. Use case Diagram

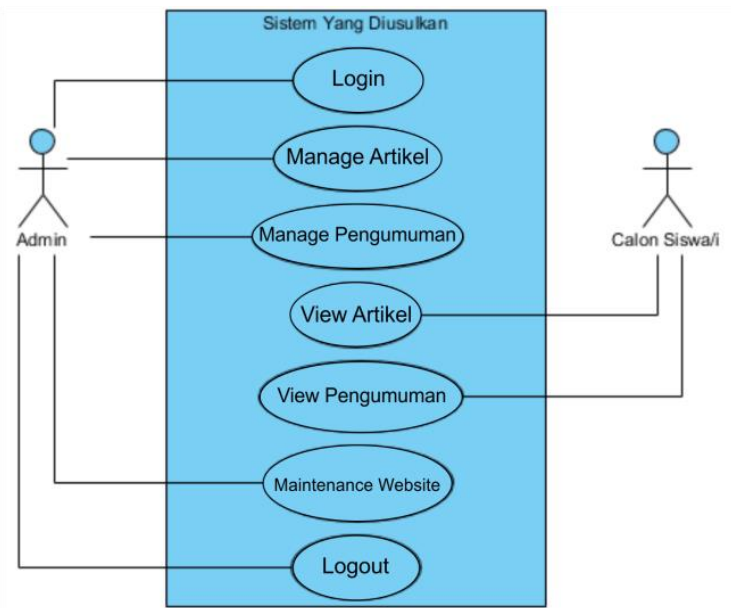

Gambar 1.Use Case Diagram

Pada gambar 1 di atas terdapat dua actor yaitu Admin dan Calon Siswa/i yang memiliki use case :

a. Admin : Login,Manage Artikel, Manage Pengumuman, Logout

b. Calon Siswa/i : View Artikel, View Pengumuman 


\subsection{Activity Diagram}

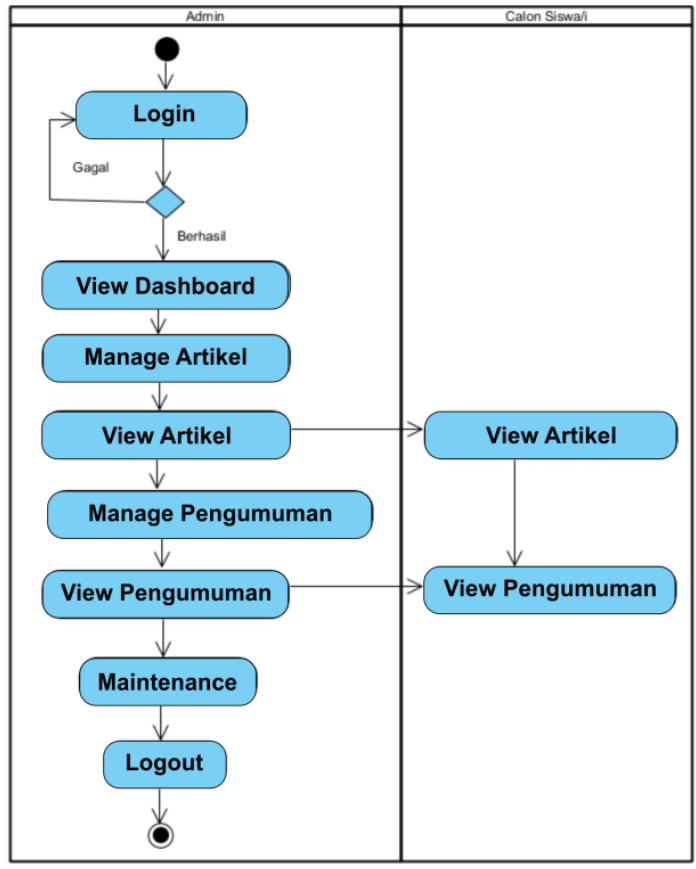

Gambar 2.Activity Diagram

Activity diagram diatas diawali dengan initial node pada Admin yang akan melakukan proses login ke website sekolah dan jika berhasil maka Admin akan memasuki dashboard namun jika gagal maka Admin harus login kembali. Kemudian Admin bisa melakukan Manage Artikel yaitu dapat melakukan edit, maupun hapus artikel yang telah di post pada website sekolah. Admin dapat melihat artikel yang ditayangkan. Kemudian pengunjung atau Calon Siswa/i dapat melihat artikel dan pengumuman yang ada pada website sekolah setelah mereka mengunjungi halaman website sekolah. Admin juga dapat melakukan Transaksi Pengumuman yaitu dapat melakukan edit dan hapus pengumuman pada website. Selain itu Admin dapat melakukan maintenance secara berkala jika dibutuhkan dan melakukan tindakan logout dari website sekolah.

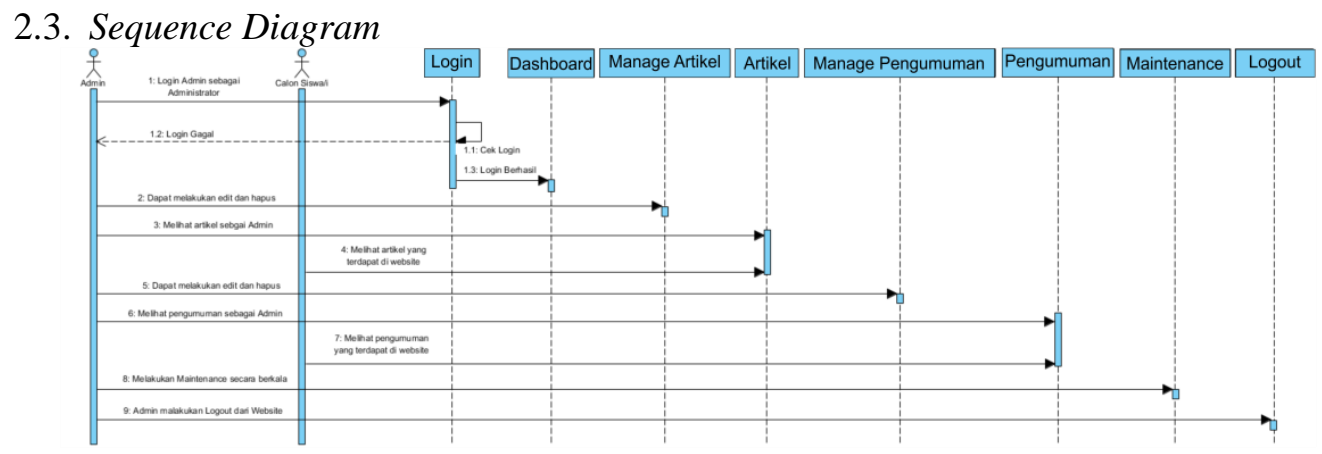

Gambar 3.Sequence Diagram

Pada gambar 3 diatas terdapat dua actor, dua lifeline dan 8 message yaitu :Login, Dashboard, Manage Artikel, Artikel, Manage Pengumuman, Pengumuman, Maintenance dan Logout. 


\section{Graphical User Interface}

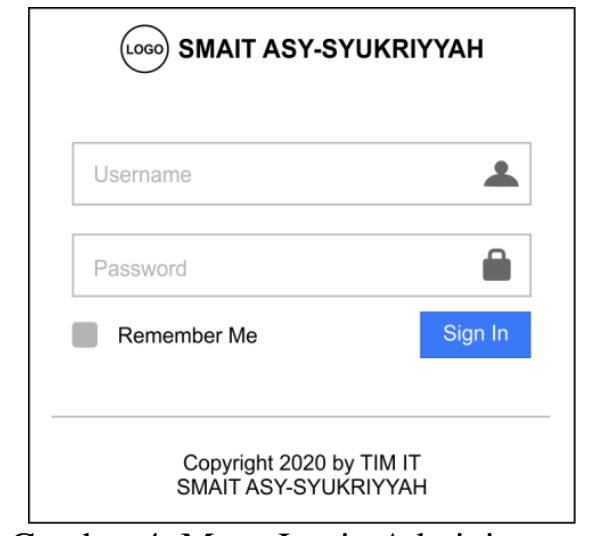

Gambar 4. Menu Login Administrator

Dari gambar diatas menunjukkan bahwa Admin harus melakukan login terlebih dahulu sebelum memasuki dashboard, ini hanya berlaku untuk Admin saja tidak untuk pengunjung website atau calon siswa/i.

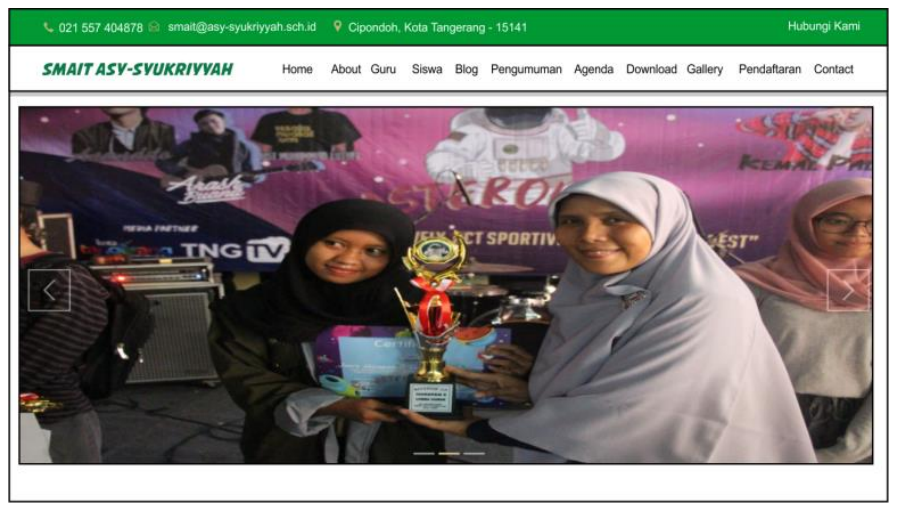

Gambar 5. Tampilan Pengunjung

Gambar diatas adalah tampilan pengunjung. Dimana para pencari informasi mengenai sekolah SMAIT Asy-Syukriyyah akan langsunng masuk beranda web sekolah.

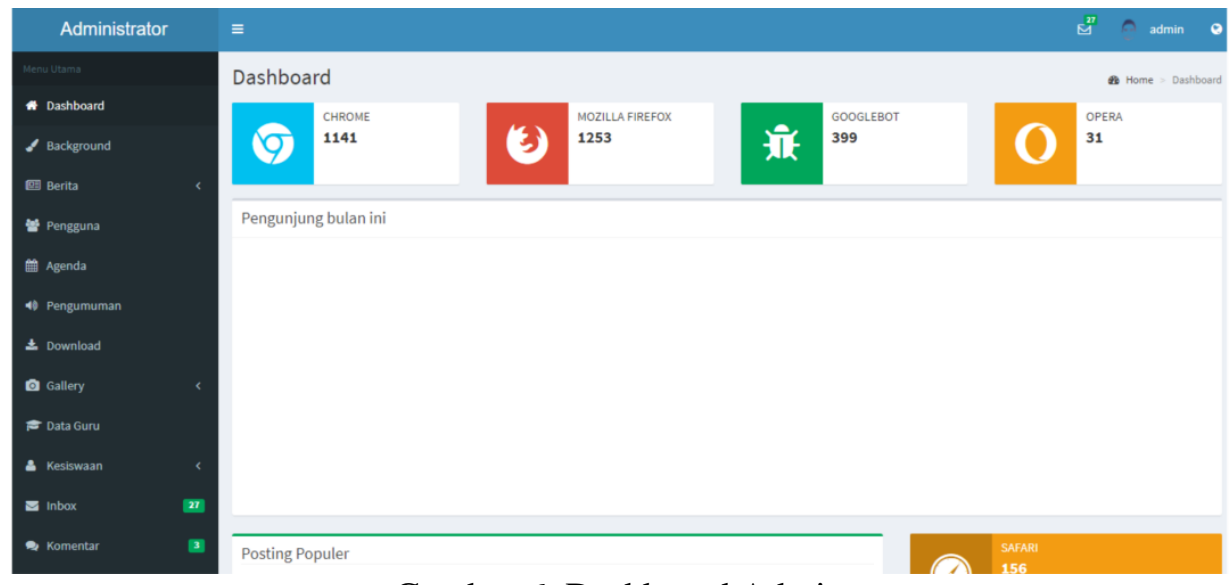

Gambar 6. Dashboard Admin

Gambar 6 diatas menerangkan informasi umum yang mengakses website sekolah tersebut jenis web browser yang mengakses. 


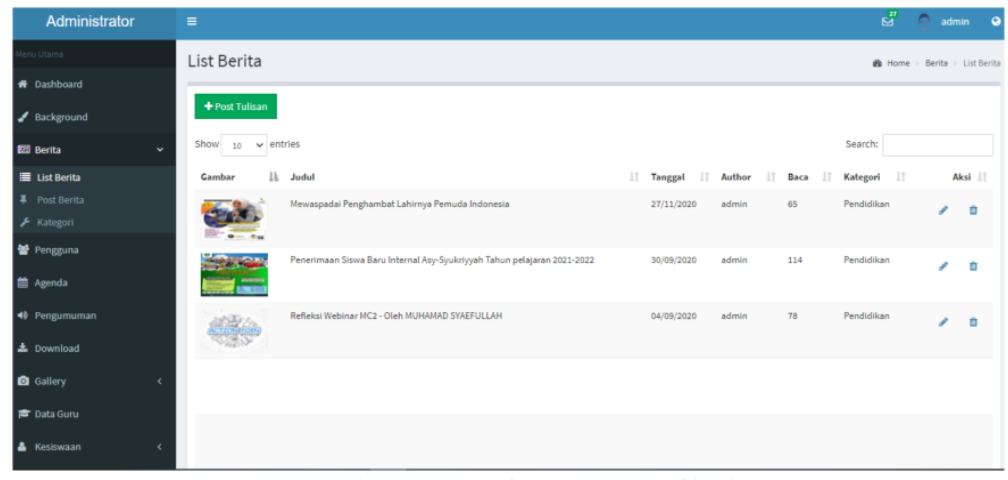

Gambar 7. Berita atau Artikel

Ini adalah tampilan untuk menambah, mengedit, dan menghapus sebuah berita atau artikel mengenai informasi sekolah.

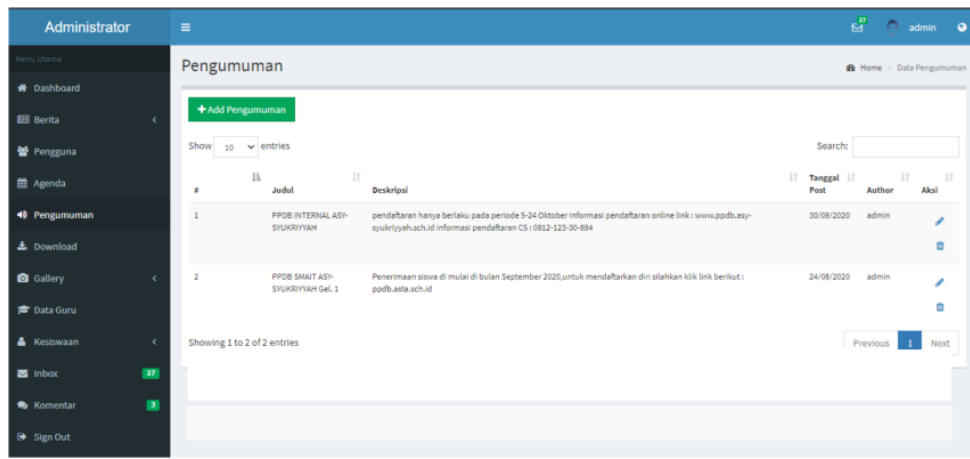

Gambar 8. Pengumuman

Tampilan pengumuman diatas memiliki fitur yang sama dengan bagian berita yaitu bisa mengedit, menambah dan menghapus pengumuman sesuai kebutuhan.

\section{KESIMPULAN}

1. Perancangan sistem usulan bisa menjadi alternatif penyelesaian masalah yang dihadapi.

2. Menghemat biaya produksi dan pemasangan serta semakin memperluas jangkauan informasi sekolah agar bisa diakses oleh banyak calon siswa/i atau pengunjung yang mencari informasi seputar SMA Islam Terpadu Asy-Syukriyyah.

\section{SARAN}

1. Memaksimalkan penggunaan sistem yang dirancang dengan melakukan maintenance website secara berkala.

2. Memperbarui informasi yang ada di dalam website agar informasi yang disajikan selalu terbaru

3. Mengharapkan Administrator selalu aktif dalam mengelola website sekolah.

\section{DAFTAR PUSTAKA}

[1] Maulani, G., Septiani, D., \& Sahara, P. N. F. (2018). Rancang Bangun Sistem InformasiInventory Fasilitas Maintenance Pada Pt. Pln (Persero) Tangerang. Icit Journal, 4(2), 156-167.

[2] Rafika, A. S., Anggiani, T. D., \& Alifah, A. D. (2018). Sistem Informasi Pembelian Barang Menggunakan Metode Value Chain. SENSI Journal, 4(1), 77-87. 
[3] Aris, A., Andriani, D., \& Romondor, A. (2016). Perancangan Aplikasi Sistem Informasi Penjualan Tiket pada PT Nur Rizky Pratama Travel Berbasis WEB. SEMNASTEKNOMEDIA ONLINE, 4(1), 4-11.

[4] Rerung, Rintho Rante. 2018. Pemrograman Web Dasar. Yogyakarta:Deepublish.

[5] Mubarak, A. (2019). Rancang Bangun Aplikasi Web Sekolah Menggunakan Uml (Unified Modeling Language) Dan Bahasa Pemrograman Php (Php Hypertext Preprocessor) Berorientasi Objek. JIKO (Jurnal Informatika dan Komputer) Ternate Vol. 02 No. 1.

[6] Rusnandi, E. (2017). Perancangan Web Sekolah Dan Ppdb Online Mts NegeriKarangsambung.INFOTECH Journal Vol. 3 No. 2.

[7] Damayanti, M. A., Sudaryanto (2020) Sistem Informasi Akademik Berbasis Web Pada Sma Negeri 13 Semarang. Journal of Information System Vol. 5, No. 2.

[8] Sumartono., Martono. B., Hidayat. S. (2020) PPM Pelatihan Pembuatan Dan Pengelolaan Web Sma Dharma Wanita 4 Taman, Sidoarjo. JPP IPTEK (Jurnal Pengabdian dan Penerapan IPTEK) Vol. 4 No. 1.

[9] Yulianto. E., Yani. A., Nurajijah. (2108) Sistem Informasi Akademik Berbasis WEB pada SMA Mandiri Balaraja - KAB.Tangerang.Jurnal TECHNO Nusa Mandiri Vol. 15, No. 1.

[10] Suhendar. B. (2018) Analisa Dan Perancangan Sistem Informasi Sekolah Berbasis WEB Di SMA 2 Kota Serang.Jurnal Informasi dan Informatika (SIMIKA) Vol. 1 No. 1.

[11] Limin Gu. (2017) Using School Websites For Home-School Communication And Parental Involvement?.NORDIC JOURNAL OF STUDIES IN EDUCATIONAL POLICY Vol. 3 No. 2. 